\title{
TÉCNICAS DE PREPARO E USO DE CALDAS ALTERNATIVAS E COMPOSTAGEM
}

\author{
Cleverson Adriano Brunetto \\ Universidade Tecnológica Federal do Paraná \\ cleve_clever17@hotmaill.com \\ Suelen Mazon \\ Universidade Tecnológica Federal do Paraná \\ mazon.suelen@gmail.com \\ Thiago de Oliveira Vargas \\ Universidade Tecnológica Federal do Paraná \\ thiagovargas@utfpr.edu.br
}

\author{
Giovana Faneco Pereira \\ Universidade Tecnológica Federal do Paraná \\ giovanafaneco@gmail.com \\ Taciane Finatto \\ Universidade Tecnológica Federal do Paraná \\ tfinatto@gmail.com
}

\begin{abstract}
Resumo
Com a necessidade de buscar alternativas para a produção de um alimento mais saudável e com baixo nível de toxicologia tanto para as pessoas como para o meio ambiente. As chamadas caldas e fertilizantes orgânicos vem com esse propósito, na qual são utilizadas na agricultura orgânica. Com este intuito as oficinas objetivaram levar aos agricultores técnicas de preparo e uso da calda bordalesa e sulfocálcica para o controle de insetos e doenças, bem como a produção de fertilizante orgânico, por meio do processo de compostagem. Realizada em assentamentos rurais no município de Itapiúna no Ceará para agricultores rurais, levou informações que podem utilizar tranquilamente em suas propriedades, principalmente por se tratar de fácil execução e com baixo custo, tanto as caldas como a compostagem, houve grande interesse pela aprendizagem por parte dos agricultores.
\end{abstract}

Palavras-chave: Calda bordalesa. Calda sulfocálcica. Compostagem.

\section{TECHNICAL PREPARATION AND USE OF ALTERNATIVE AND COMPOSTING}

\section{TAILS}

\begin{abstract}
With the need to find alternatives to the production of healthier food and low level of toxicology for both people and the environment. Calls syrups and organic fertilizers come for this purpose, which are used in organic agriculture. To this end the workshops aimed to lead the preparation techniques farmers and use of Bordeaux mixture and sulfur to control insects and diseases, and the production of organic fertilizer through the composting process. Held in rural settlements in Itapiúna municipality of Ceará for rural farmers, led information that can be used quietly in their properties, especially because it is easy to perform and inexpensive, both tails as composting, there was great interest in part by learning farmers.
\end{abstract}

Keywords: Bordeaux mixture. Lime sulfur. Composting.

\section{PREPARACIÓN TÉCNICA Y EL USO DE COLAS ALTERNATIVAS Y COMPOSTAJE}

Resumen

Con la necesidad de encontrar alternativas a la producción de alimentos sanos y de bajo nivel de la toxicología para las personas y el medio ambiente. Llamadas jarabes y fertilizantes orgánicos vienen para este fin, que se utilizan en la agricultura orgánica. Con este fin, los talleres dirigidos para dirigir las técnicas de preparación de los agricultores y el uso de 
caldo bordelés y el azufre para controlar insectos y enfermedades, y la producción de abono orgánico a través del proceso de compostaje. Celebrada en asentamientos rurales en el municipio Itapiúna de Ceará para los agricultores rurales, llevó la información que se puede utilizar tranquilamente en sus propiedades, sobre todo porque es fácil de realizar y de bajo costo, ambas colas como el compostaje, hubo gran interés en parte por el aprendizaje agricultores.

Palavras clave: Caldo bordelés. Sulfuro de cal. Compostaje. 
Técnicas de preparo e uso de caldas alternativas e compostagem

\section{INTRODUÇÃO}

Cada vez mais as pessoas estão buscando alimentos mais saudáveis, essa preocupação com a saúde alimentar é efeito dos altos índices de resíduos de agrotóxicos que são encontrados nos alimentos. Segundo a Anvisa (2014), 67\% dos alimentos analisados tem algum tipo de resíduo de agrotóxico, na qual 25\% das amostras apresentarem resíduos de produtos não autorizados, ou autorizados, mas em concentrações acima do Limite Máximo de Resíduo (LMR), dentre os alimentos com os maiores resíduos se destaca a alface seguido da abobrinha, tomate e uva.

Nesse contexto há a necessidade de buscar alternativas para a produção de um alimento mais saudável e com baixo nível de toxicologia tanto para as pessoas como para o meio ambiente. As chamadas caldas e fertilizantes orgânicos vem com esse propósito, na qual são utilizadas na agricultura orgânica.

As caldas são utilizadas desde muito tempo como a calda bordalesa descoberta acidentalmente no ano de 1882 na França resultante da neutralização de sulfato de cobre com excesso de hidróxido de cálcio, onde era utilizada para evitar furtos de uva, porém tendo efeito no controle de míldio da videira, a mesma vem sendo utilizada até os dias de hoje com excelente controle em diversas doenças (MICHEREFF, 2001).

A calda bordalesa é utilizada em hortas e pomares, para o controle de doenças causadas por fungos como míldio, ferrugem, requeima, pinta preta, cercosporiose, antracnose, manchas foliares, entre outras em diversas culturas, tendo efeito secundário contra bacterioses e efeito repelente contra alguns insetos como: cigarrinha verde, cochonilhas, trips e pulgões (MOTTA, 2008).

A calda sulfocálcica possui ação inseticida contra insetos sugadores, como tripes e cochonilhas, tem efeito acaricida e fungicida no controle de oídios e ferrugens, é utilizada também como desinfecção de ferimentos de poda para auxiliar na cicatriz (MOTTA, 2008).

As caldas além de controlarem de forma significativa diversos insetos e doenças são de fácil preparo e também com um custo muito baixo, na qual o agricultor pode estar fazendo em sua própria propriedade, utilizando quando necessário.

A compostagem é uma outra forma de diminuir os custos de produção, na qual é um processo biológico em que os microrganismos transformam a matéria orgânica, como estrume e folhas em um composto orgânico semelhante ao solo e que pode ser utilizado como adubo, tem como vantagem a reutilização dos nutrientes presentes nos materiais da propriedade. 
Técnicas de preparo e uso de caldas alternativas e compostagem

Com este intuito as oficinas objetivaram levar aos agricultores técnicas de preparo e uso da calda bordalesa e sulfocálcica para o controle de insetos e doenças e também a produção de fertilizante orgânico, por meio do processo de compostagem.

\section{MATERIAIS E MÉTODOS}

A Operação Mandacaru ocorreu no Estado do Ceará mais especificadamente no município de Itapiúna. A região é caracterizada pelas elevadas temperaturas ao longo do ano, associadas à baixa média de precipitação e às chuvas com distribuição irregular. As oficinas ocorreram em dois assentamentos rurais, Massapê e Curupaiti, este último localizado no distrito de Itans.

O composto orgânico foi produzido nos assentamentos rurais e, teve como material de origem capim triturado e esterco bovino. O composto foi montado em camadas, numa proporção 2:1 (v/v). Os materiais foram compostados em pilhas com revolvimento manual (SANTOS et al., 2003).

Para o preparo da calda bordalesa utilizou-se sulfato de cobre e cal virgem, sendo 200 gramas de cada. Em um balde de plástico, com 10 litros de água, dissolve as 200 gramas de cal virgem, colocado no dia anterior (para dissolver), em um saco de pano. Em outro balde, com 10 litros de água dissolve as 200 gramas de sulfato de cobre, posteriormente despeja os 10 litros da solução de sulfato de cobre no balde com o preparado da cal, agitando a mistura (MOTTA, 2008).

Para o preparo da calda sulfocálcica, utilizou-se uma lata de 20 litros e coloca a cal virgem e em 10 litros de água depois, levar ao fogo para ferver, ao iniciar a fervura, adicionar o enxofre, marcando na lata o nível inicial, mexer por aproximadamente 1 hora, sempre mantendo a fervura e nível da água marcado inicialmente. A calda deve ficar grossa, com coloração pardoavermelhada (MOTTA, 2008).

\section{RESULTADOS E ANÁLISES}

A compostagem foi uma alternativa de adubação aos agricultores assentados, na qual representa uma diminuição no custo de produção visto que há um aproveitamento dos resíduos 
Técnicas de preparo e uso de caldas alternativas e compostagem

da própria propriedade, formando um composto que fornece os nutrientes para as plantas de uma forma mais controlada, durando por mais tempo, melhorando também a qualidade do solo.

Todos os restos de lavouras, capins, estercos de animais, aparas de gramas, folhas, galhos, resíduos de agroindústria (restos de abatedouro, tortas e farinhas) podem ser usados. É importante o aproveitamento dos materiais que existem na propriedade, diminuindo o custo da produção do composto.

O composto orgânico é um fertilizante originário desse processo de tratamento de resíduos agrícolas denominados compostagem. O composto pode ser utilizado para fertilizar o solo visando à nutrição de culturas e contribui com outras propriedades importantes do solo como aumento do teor de matéria orgânica, melhoria da retenção de água e porosidade. Desta maneira, os agricultores poderão incluir em suas práticas agrícolas o processo de compostagem e com o passar do tempo, verificarem que o composto não só beneficiará as plantas bem como todo o meio ambiente.

As comunidades apresentavam problemas severos com ataques de cochonilhas em diversas frutíferas, causando grandes danos na produção bem como no desenvolvimento, pois não utilizavam nenhum produto para o controle, as caldas ensinadas foram de grande importância, uma vez que o seu controle é eficaz para esta como demais espécies de insetospragas.

O uso intensivo de agrotóxico na agricultura convencional tem proporcionado diversos problemas tais como: a contaminação dos alimentos, do solo, da água e dos animais, a intoxicação de agricultores, a resistência de patógenos, de pragas e de plantas invasoras a certos pesticidas, o desequilíbrio biológico, alterando a ciclagem de nutrientes e da matéria orgânica, eliminação de organismos benéficos, e a redução da biodiversidade, entre outras.

\section{CONSIDERAÇÕES FINAIS}

Os objetivos a que nos propusemos com a realização deste trabalho foram satisfatórios, uma vez que os agricultores atingidos, certamente utilizarão o conhecimento adquirido, desta forma a produção de seus produtos ganha uma nova técnica, podendo ter incrementos de produtividade superiores aos que tinham antes. 
Técnicas de preparo e uso de caldas alternativas e compostagem

Por mais que as técnicas repassadas são utilizadas desde os seculos passados, ainda fazem grande diferença no uso da agricultura atual, uma vez que são alternativas baratas e de fácil preparo, sendo uma alternativa na produção de alimentos mais saudáveis.

\section{REFERÊNCIAS}

ANVISA. AGENCIA NACIONAL DE VIGILÂNCIA SANITÁRIA. Programa de análise de resíduos de agrotóxicos em alimentos. Outubro de 2014. Disponível em: $<$ http://portal.anvisa.gov.br/wps/wcm/connect/d67107004634368583a5bfec1b28f937/Relat\% $\%$ C3\%B3rio+PARA+2012+2\%C2\%AA+Etapa+-+17_10_14-Final.pdfMOD=AJPERES $>$.

Acesso em: 14 de agosto de 2015.

MICHEREFF, S. J. Fundamentos de Fitopatologia. Recife - PE, 2001. Disponível em: $<$ https:www.ccta.ufcg.edu.br\%2Fadmin.files.action.php $\% 3$ Faction $\% 3$ Ddownload $\% 26 \mathrm{id} \% 3 \mathrm{D} 208$ 4\&ei=Zm_OVaf1CYXFwAS4yKHIBQ\&usg=AFQjCNEjg8qxK_JNnKV1nFb6LQp_pxYTHg \&sig2=GKZ1QooTccsjTEHBNJHKAw\&bvm=bv.99804247,d.Y2I>. Acesso em: 14 de agosto de 2015.

MOT'TA, I. S. Calda Bordalesa: Utilidades e preparo. Dourados, MS 2008. Disponível em: <http://www.cpao.embrapa.br/publicacoes/online/zip/FOL200837.pdf>. Acesso em: 14 de agosto de 2015.

Calda Sulfocálcica: Preparo e indicações. Dourados, MS 2008. Disponível em: <http://www.cpao.embrapa.br/publicacoes/online/zip/FOL200836.pdf >. Acesso em: $14 \mathrm{de}$ agosto de 2015.

SANTOS, R. H. S.; BARRELLA, T. P.; DINIZ, E. R. Compostagem. Brasília: SENAR, 2003. $59 \mathrm{p}$. 